\title{
Nuevos paradigmas y desafíos en la prevención y control del cáncer de cuello uterino en América Latina
}

\author{
Maribel Almonte, PhD, (1) Raúl Murillo, MD, (2) Gloria Inés Sánchez, PhD, , José Jerónimo, MD, ${ }^{(4)}$ Jorge Salmerón, Dr Sc, ${ }^{(5)}$ \\ Catterina Ferreccio, MD, (6) Eduardo Lazcano-Ponce, Dr Sc, ${ }^{(7)}$ Rolando Herrero, PhD. ${ }^{(8)}$
}

\begin{abstract}
Almonte M, Murillo R, Sánchez GI, Jerónimo J, Salmerón J, Ferreccio C, Lazcano-Ponce E, Herrero R. Nuevos paradigmas y desafíos en la prevención y control del cáncer de cuello uterino en América Latina. Salud Publica Mex 2010;52:544-559.
\end{abstract}

\section{Resumen}

El cáncer de cuello uterino sigue siendo un problema de salud pública en Latinoamérica. El uso de la citología para la detección de lesiones pre-cancerosas no ha tenido mayor impacto en las tasas de incidencia y mortalidad, que aún se mantienen altas en la región. La disponibilidad de nuevas técnicas de tamizaje para la detección de lesiones pre-cancerosas y de vacunas altamente eficaces que previenen casi todas las lesiones relacionadas con VPH-16 y VPH-I8 en mujeres no expuestas previamente al virus representan una gran oportunidad para la prevención del cáncer de cuello uterino en la región. En este manuscrito resumimos la evidencia científica y la experiencia de la región en i) el uso de pruebas de VPH y de la inspección visual después del ácido acético (IVAA) en tamizaje primario, y ii) la implementación de programas de vacunación en adolescentes. Finalmente enumeramos una serie de recomendaciones adecuadas para distintos escenarios. La factibilidad de implementar un programa nacional de prevención de cáncer de cuello uterino exitoso y sostenible

\author{
Almonte M, Murillo R, Sánchez GI, Jerónimo J, Salmerón J, \\ Ferreccio C, Lazcano-Ponce E, Herrero R. \\ New paradigms and challenges in cervical cancer \\ prevention and control in Latin America. \\ Salud Publica Mex 2010;52:544-559.
}

\begin{abstract}
Cervical cancer continues to be a significant health problem in Latin America. The use of conventional cytology to detect precancerous cervical lesions has had almost no major impact on reducing cervical cancer incidence and mortality rates, which are still high in the region. The availability of new screening tools to detect precancerous lesions provide great opportunities for cervical cancer prevention in the region, as do highly efficacious HPV vaccines able to prevent nearly all lesions associated with HPV- 16 and -18 when applied before viral exposure. This paper summarizes the scientific evidence and regional experiences related to:i) the use of HPV testing and visual inspection after the application of acetic acid (VIA) in primary screening and ii) the implementation of adolescent HPV vaccination programs. Finally, we outline a number of recommendations for different resource settings. The feasibility of implementing successful and sustainable national cervical cancer prevention programs in Latin American countries in the region will depend on health priorities and the availability
\end{abstract}

(I) Cancer Research UK Centre for Epidemiology, Mathematics \& Statistics, Wolfson Institute of Preventive Medicine, Queen Mary University of London. London UK

(2) Subdirección Investigaciones y Salud Pública, Instituto Nacional de Cancerología. Bogotá, Colombia

(3) Grupo Infección y Cáncer, Facultad de Medicina, Universidad de Antioquia. Medellín, Colombia

(4) PATH. Seattle,WA, USA

(5) Unidad de Investigación Epidemiológica y en Servicios de Salud, Instituto Mexicano del Seguro Social. Cuernavaca, Morelos, México

(6) Departamento de Salud Pública, Escuela de Medicina, Pontificia Universidad Católica de Chile. Santiago, Chile

(7) Instituto Nacional de Salud Pública. Cuernavaca, Morelos, México

(8) Proyecto Epidemiológico Guanacaste, Fundación INCIENSA. San José, Costa Rica

Fecha de recibido: 27 de septiembre de 2010 - Fecha de aceptado: 22 de octubre de 2010 Solicitud de sobretiros: Maribel Almonte, MPH, MSc, PhD. Cancer Research UK Centre for Epidemiology, Mathematics \& Statistics, Wolfson Institute of Preventive Medicine, Queen Mary University of London, Charterhouse Square, London ECIM 6BQ Correo electrónico:m.almonte@qmul.ac.uk 
en países latinoamericanos dependerá de las prioridades de salud, la infraestructura y personal de salud disponible, determinadas luego de un riguroso análisis situacional local.

Palabras clave: cancer de cuello uterino; tamizaje cervical; virus de papiloma humano (VPH); programas de vacunación; tecnicas de tamizaje of infrastructure and health personnel-as determined by rigorous local situational analysis.

Keywords: cervical cancer; cervical screening; human papillomavirus (HPV); vaccination programmes; screening techniques
$E^{1}$ uso de la citología cérvico-vaginal convencional ha logrado reducir la mortalidad por cáncer de cuello uterino en países desarrollados, ${ }^{1,2}$ tanto cuando es aplicada en programas organizados de detección como cuando se tamiza una proporción grande de mujeres de manera oportunista. ${ }^{3}$ Este no ha sido el caso de América Latina, donde a pesar de la disponibilidad de la prueba de Papanicolaou, alrededor de 32000 mujeres mueren cada año por cáncer de cuello uterino. ${ }^{4}$ Estudios recientes han demostrado que aún con adecuado control de calidad, la citología convencional tiene en promedio una sensibilidad de 53\% (95\%IC: 48.6-57.4\%) en Europa y Estados Unidos. ${ }^{5}$ Esta observación sugiere que el éxito de algunos de estos programas no reside en la sensibilidad de la prueba, sino en la repetición constante de la misma y en el seguimiento sistematizado de mujeres con anormalidades citológicas que aseguran el diagnóstico y el tratamiento definitivo de lesiones detectadas, modelo que no se ha logrado replicar en regiones con escasos recursos.

La identificación del virus del papiloma humano (VPH) como la causa principal y necesaria del cáncer de cuello uterino, ${ }^{6,7}$ y el desarrollo de pruebas moleculares y de vacunas profilácticas para la detección y prevención de esta infección han abierto nuevas perspectivas para el control de este cáncer.

A partir de la utilización de la evidencia internacional actual y, en particular, la experiencia de los países de la región, en este artículo se discuten los desafíos que enfrentan los países de Latinoamérica para establecer programas sostenibles de prevención de cáncer de cuello uterino, al implementar programas de tamizaje, vacunación, o ambos, de acuerdo con los recursos disponibles en distintos escenarios.

\section{Incidencia y mortalidad por cáncer del cuello uterino en América Latina}

El cáncer de cuello uterino es el segundo cáncer más frecuente en mujeres en el mundo con $86 \%$ de los casos y $88 \%$ de las muertes en países en vías de desarrollo ${ }^{8}$ y es la causa más importante de años de vida perdidos (por cáncer) entre las mujeres de América Latina y el
Caribe, ${ }^{9}$ donde se concentra $13 \%$ de los casos y $12 \%$ de las muertes que ocurren anualmente en el mundo. Si no se mejoran los programas de prevención, se ha estimado que el número de casos de cáncer de cuello uterino se incrementará en la región de 68000 en el año 2008 a 126000 en el año 2025, simplemente por el crecimiento y envejecimiento de la población. ${ }^{10}$

El cáncer de cuello uterino constituye uno de los ejemplos claros de inequidad en salud y la carga de la enfermedad difiere ampliamente entre países y en regiones dentro de los mismos. Así, el problema es más grave en Nicaragua, Honduras, El Salvador y Bolivia, donde las tasas de incidencia son superiores a 35 por 100 000, mientras que en Puerto Rico es tan sólo de 7.5 (figura 1), la mitad de la tasa global mundial (15.3). Igualmente, la mortalidad es mayor en regiones con deficientes condiciones sociales y económicas, como los extremos norte y sur de Argentina, algunas zonas centrales de Colombia y el sur de Chile (figura 2). Otro tanto sucede en el sur de México (figura 3). ${ }^{11}$ Los datos disponibles sobre tendencias de la incidencia muestran una reducción en Brasil, Colombia, Costa Rica, Ecuador y Puerto Rico (figura 4); no obstante, debe tenerse en cuenta que los registros poblacionales de la región, con excepción de los de Costa Rica y Puerto Rico, cubren áreas urbanas de algunas ciudades y por lo tanto pueden no reflejar la situación general de las áreas con menor acceso a los servicios de salud que posiblemente tengan una mayor carga de enfermedad. El panorama es distinto cuando se evalúan tendencias en la mortalidad por cáncer de cuello uterino. Puerto Rico es el único país que ha mantenido una tasa por debajo de cuatro muertes por 100000 desde los años setenta. Chile, Costa Rica, México y Colombia muestran reducciones significativas pero aún tienen tasas de mortalidad sobre 5 por 100 000, y países que ya tenían tasas de mortalidad por debajo de 10 por 100000 en los setenta como Cuba, Argentina, Brasil y Uruguay, no han logrado mayor descenso en el riesgo de muerte por cáncer de cuello uterino (figura 5). Las limitaciones de la cobertura de los registros, las deficiencias en los sistemas de estadísticas vitales y la carencia de información sobre el estadío de los tumores invasores al momento del diagnóstico no 


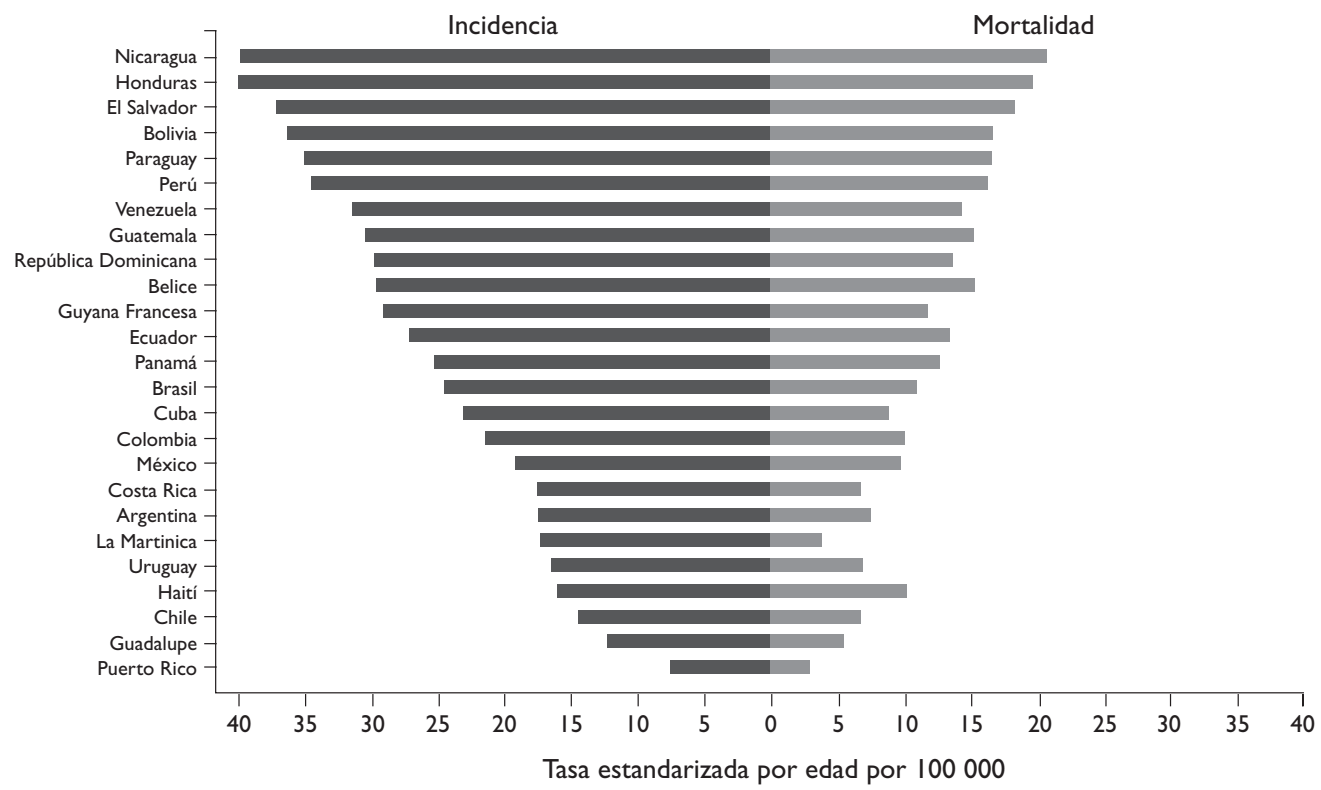

Fuente: Ferlay J, Shin H, Bray F, Forman D, Mathers C, Parkin DM. GLOBOCAN 2008, Cancer Incidence and Mortality Worldwide: IARC CancerBase No. 10 [Internet]. Lyon, France: International Agency for Research on Cancer, 2010.Available at: http://globocan .iarc.fr; 2010. ${ }^{8}$

\section{Figura I. InCIDENCIA Y MORTALIDAd POR CÁNCER de CUELLO UTERINo en AMÉRICA LATINA}

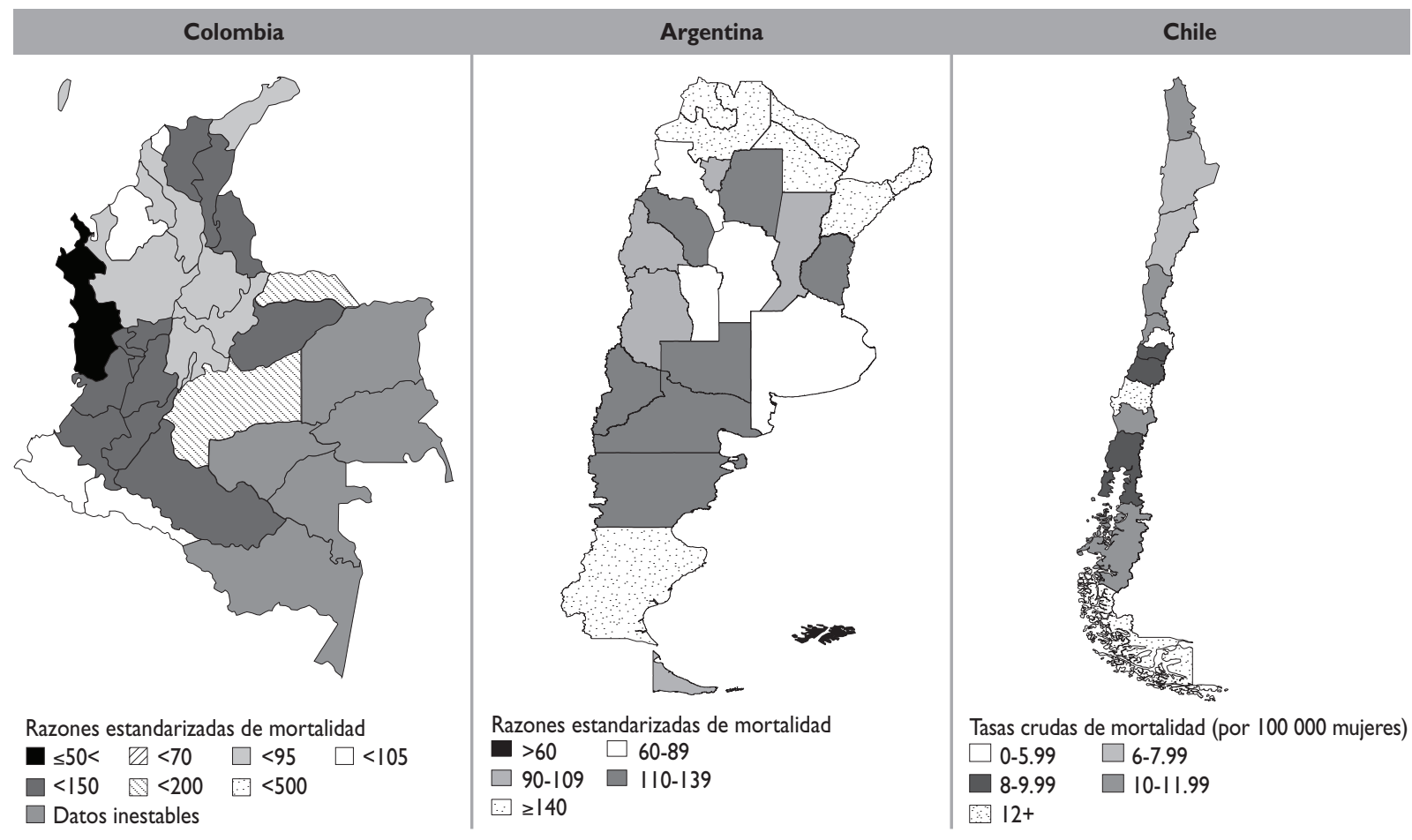

Adaptada y reimpresa de Vaccine 26 Suppl II. Parkin DM, Almonte M, Bruni L, Clifford G, Curado MP, Piñeros M. Burden and trends of type-specific human papillomavirus infections and related diseases in the Latin America and Caribbean region. Fig 3, página L4. Copyright 2008, con permiso de Elsevier ${ }^{10}$

Figura 2.Variación de las tasas de mortalidad por cáncer de cuello uterino en Colombia,Argentina y Chile. 


\section{México}

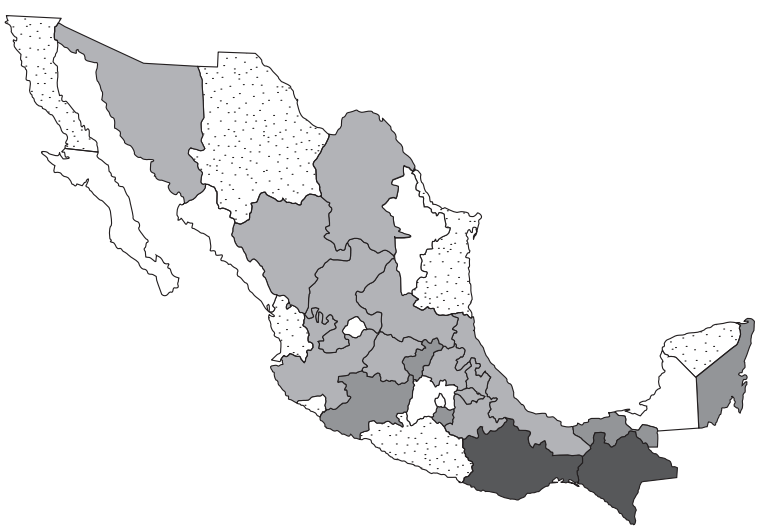

Tasas crudas de mortalidad (por 100000 mujeres)

\begin{tabular}{|c|}
\hline$\square$ 5.3-7.9 \\
\hline$\square 10.8-12.6$ \\
\hline
\end{tabular}

Fuente: referencia II

Figura 3. Variación de las tasas de mortalidad por cáncer de cuello uterino en México permiten valorar si los programas de tamización han tenido un efecto real o si la reducción de las tasas de cáncer de cuello uterino se debe a mejoras sociales y/o a la disminución de las tasas de natalidad. A pesar de la deficiencia de los datos mencionados anteriormente, la razón mortalidad-incidencia $(\mathrm{M} / \mathrm{I})$ puede ser utilizada como indicador indirecto del desempeño del tamizaje y los servicios de salud en el control del cáncer de cuello uterino. En el cuadro I se muestran las razones M/I de la región. ${ }^{8}$ En el extremo superior se encuentra Haití con una razón de 0.63 , que refleja la carencia o pobre eficacia del programa de tamizaje, mientras que en el extremo inferior están Cuba, Costa Rica, Puerto Rico y La Martinica con razones M/I por debajo de 0.40 , reflejando posiblemente un acceso a los servicios de salud más eficiente al ser países más pequeños.

\section{Historia natural del VPH y las neoplasias cervicales}

La infección por virus de papiloma humano (VPH) es una de las infecciones transmitidas sexualmente más comunes en ambos sexos, y la mayoría de las personas la adquieren, usualmente, cerca del inicio de la actividad sexual.

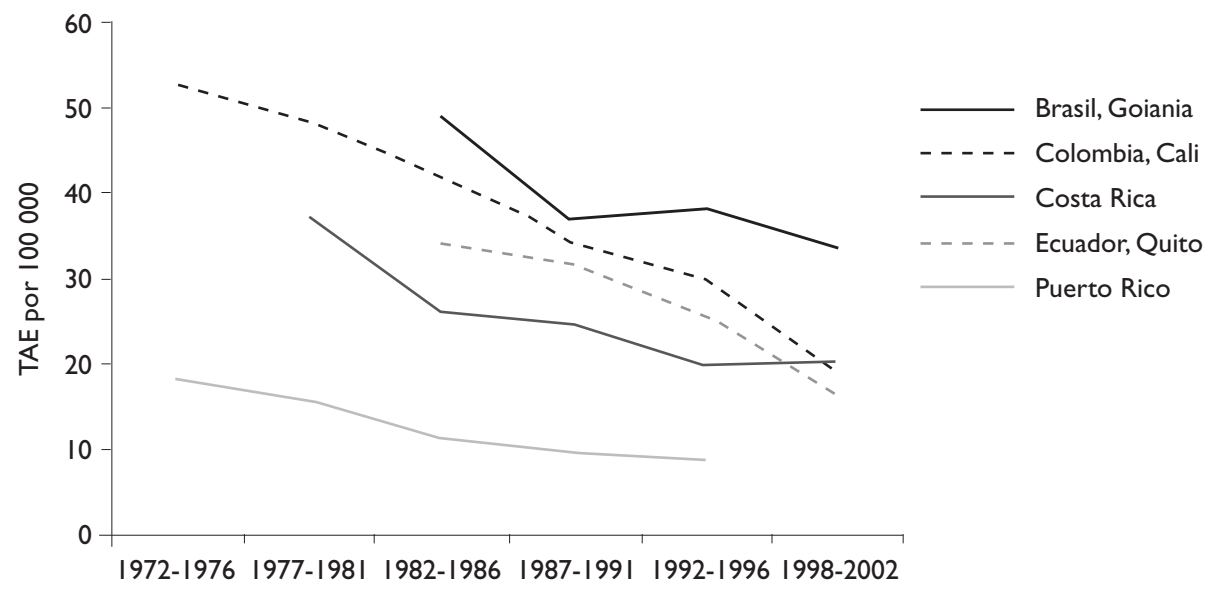

Fuente: Cancer Incidence in Five Continents Vol. IV - Vol. IX

Se incluyeron registros de cáncer de la región que reportaran al menos en cuatro volúmenes de Cancer Incidente in Five Continents. Los periodos en la gráfica corresponden a los reportados por el Registro Poblacional de Cáncer de Cali que es el único con datos en toda la serie. Los periodos específicos son: Goiania 88-89, 90-93, 95-98, 99-02; Costa Rica 80-82, 84-87, 88-92, 95-96, 98-02; Quito 85-87, 88-92, 93-97, 98-02; Puerto Rico 73-77, 78-82, 83-87, 88-91, 92-93

TAE:Tasa ajustada por edad

\section{Figura 4. Tendencia de la incidencia de cáncer en países seleccionados de América Latina}



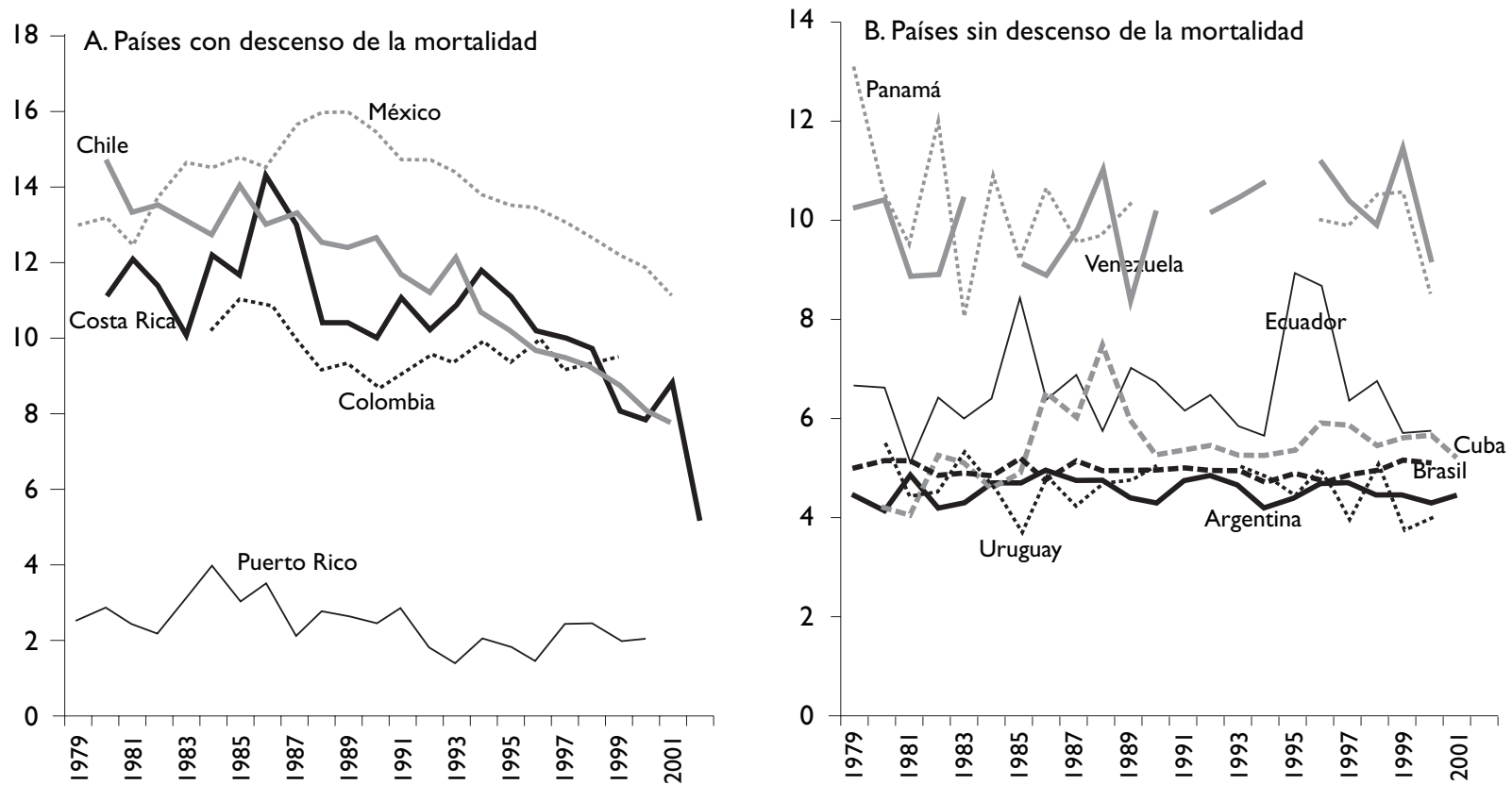

Figura 5. Tendencia de la mortalidad por cáncer de cuello uterino en países seleccionados de América Latina

CuAdro I

\section{RAZÓN MORTALIDAD/INCIDENCIA POR PAÍS}

\begin{tabular}{lc} 
País & Razón mortalidadlincidencia \\
Haití & 0.63 \\
\hline Nicaragua & 0.52 \\
\hline Honduras & 0.52 \\
\hline Belice & 0.52 \\
\hline México & 0.51 \\
\hline Guatemala & 0.50 \\
\hline Panamá & 0.50 \\
\hline El Salvador & 0.49 \\
\hline Ecuador & 0.49 \\
\hline Paraguay & 0.47 \\
\hline Perú & 0.47 \\
\hline Colombia & 0.47 \\
\hline Bolivia & 0.46 \\
\hline Venezuela & 0.46 \\
\hline República Dominicana & 0.46 \\
\hline Chile & 0.46 \\
\hline Brasil & 0.44 \\
\hline Guadalupe & 0.44 \\
\hline Argentina & 0.42 \\
\hline Uruguay & 0.41 \\
\hline Guyana Francesa & 0.40 \\
\hline Cuba & 0.39 \\
\hline Costa Rica & 0.38 \\
\hline Puerto Rico & 0.37 \\
\hline La Martinica & 0.21 \\
\hline
\end{tabular}

La infección inicia en las células basales de la zona de transformación cervical, pero la respuesta inmune innata tiende a ser retardada porque no existe fase citopática, y los viriones infectantes y antigénicos se producen en las capas más diferenciadas del epitelio. ${ }^{12}$ Sin embargo, la mayoría de las infecciones son controladas por la respuesta inmune celular. Solamente en aproximadamente la mitad de los expuestos hay seroconversión, y se desconoce el grado en que la infección natural protege contra infecciones recurrentes o facilita el control inmunológico de las mismas.

Existen más de 100 tipos de VPH, y su variabilidad genética se relaciona con su carcinogenicidad. ${ }^{13}$ Los tipos virales en las especies A7 (VPH 18, 39, 45, 59 y 68) y A9 (VPH 16, 31, 33, 35, 52 y 58) incluyen la mayoría de los tipos llamados de alto riesgo, y los tipos 16 y 18 causan cerca de $60-70 \%$ de todas las lesiones precursoras y los cánceres invasores a nivel mundial, con pocas variaciones regionales. Los tipos 16 y 18 son más agresivos, con desarrollo de lesiones más temprano ${ }^{14}$ y mucho mayor riesgo que otros tipos oncogénicos. ${ }^{15}$ Los adenocarcinomas son causados en mayor proporción por el VPH 18. ${ }^{16}$

La infección se acompaña algunas veces de neoplasias cervicales intraepiteliales (NIC), con cambios característicos en el núcleo y citoplasma, clasificadas histológicamente en NIC 1, 2 y 3 según el grado de afectación del epitelio que a su vez determina el tipo de células detectables en células exfoliadas. Las lesiones 
de NIC1 son la manifestación de infección reciente por VPH y regresan tan frecuentemente como las infecciones sin manifestaciones celulares. La mayoría de las infecciones por VPH prevalentes en una población desaparecen en los siguientes tres años, ${ }^{17,18}$ aunque las producidas por VPH 16 tienden más a la persistencia y progresión. Las NIC3 son verdaderas lesiones precancerosas y tienen alto riesgo de progresión a cáncer invasor, a pesar de que un porcentaje regresa espontáneamente. ${ }^{19}$ Las NIC2 son una categoría intermedia y poco reproducible que probablemente incluye NIC1 y NIC3 ${ }^{20}$ A nivel citológico, las lesiones de NIC1 se manifiestan como lesiones intraepiteliales de bajo grado, y las NIC2 y NIC3 como lesiones intra-.epiteliales de alto grado, según la clasificación de Bethesda. ${ }^{21}$

La prevalencia de la infección por VPH se caracteriza en América Latina por un primer pico cercano a 25-30\% antes de los 25 años, representando infecciones recientes. Esta prevalencia decrece con la edad pero en varios estudios en esta región se ha observado un segundo pico en mayores de 55 años, ${ }^{22-25}$ lo cual podría ser explicado por el comportamiento sexual de las mujeres o de sus compañeros, un efecto de cohorte o la reactivación de infecciones latentes. En Guanacaste, Costa Rica, se demostró asociación entre persistencia viral y respuesta disminuida a estimulación de linfocitos en mayores de 45 años, sugiriendo la posibilidad de alteraciones inmunológicas como explicación del segundo pico de prevalencia. ${ }^{26}$

Los factores para que una infección persista y/o progrese a lesiones pre-cancerosas incluyen características inmunológicas del huésped, como sus antígenos de histocompatibilidad, que podrían influir en la respuesta inmune, el número de embarazos, el tabaquismo, el uso prolongado de anticonceptivos hormonales, la inflamación crónica causada por otros agentes infecciosos y posiblemente la dieta y otros factores ambientales y genéticos. La mayoría de estos factores han sido ampliamente estudiados y se consideran co-factores establecidos de la infección por $\mathrm{VPH}$, que está establecida como una causa necesaria pero no suficiente para el desarrollo del cáncer de cuello uterino.

\section{Situación actual de la prevención del cáncer de cuello uterino en América Latina}

El uso de la citología ha tenido muy poco impacto en la incidencia y mortalidad de cáncer de cuello uterino en América Latina. Esto se puede explicar principalmente por la baja sensibilidad de la prueba y el elevado porcentaje de mujeres con anormalidades citológicas que no son evaluadas y/o tratadas adecuadamente. Las limitaciones inherentes a la naturaleza de la prueba requieren garantizar la obtención de un espécimen de alta calidad con fijación y tinción apropiada. Este proceso es muy complejo e incluye ciertos requerimientos en la mujer a tamizarse y un adecuado entrenamiento del personal recolector de muestra. Aún en condiciones ideales (mujeres bien informadas, uso de instrumento de recolección apropiado para las características fisiológicas del cérvix de la mujer y fijación adecuada de la muestra en el tiempo requerido), la muestra recolectada puede no ser óptima. Una vez en el laboratorio, el resultado de la citología depende enteramente del ojo del citotecnólogo, por lo que es fundamental tener sistemas de control de calidad internos y externos. Lograr la calidad necesaria para garantizar un buen resultado, y más aún mantenerla, es muy difícil y requiere constante inversión en el sistema. En tres estudios en la región la sensibilidad de la citología fue de $30-40 \%{ }^{27-29}$ y en otros dos entre $50-60 \% .30,31$ Estos resultados fueron obtenidos en condiciones de estudio y no en situaciones reales de prestación de servicios, donde quizás el desempeño de la citología es aún más insatisfactorio.

En consecuencia, desde la década de los 90, se han venido estudiando pruebas de tamizaje alternativas, principalmente la detección del ADN del VPH y la inspección visual después de la aplicación del acido acético (IVAA). Más recientemente se han evaluado estrategias de tamizaje combinando diversas pruebas con esquemas de diagnóstico y tratamiento de lesiones detectadas que se realizan en una o dos visitas al servicio de salud y aseguran una mayor adherencia y costo-efectividad de los programas de tamizaje.

\section{Detección de VPH-ADN como tamizaje primario}

La validez y precisión de la prueba que reconoce los 13 genotipos de alto riesgo del VPH ha sido evaluada extensamente en varios estudios en Latinoamérica y en el mundo. Se ha demostrado consistentemente que la prueba es más sensible que la citología y el IVAA y menos específica que la citología para la detección de lesiones de alto grado, y que este problema de baja especificidad es más agudo en mujeres menores de 30 años. Como consecuencia de esta observación, Estados Unidos $^{32}$ y México ${ }^{28}$ han introducido la prueba como método adjunto a la citología o como método primario (seguido de triaje con citología) en mujeres mayores de 30 años; otros países están evaluando rigurosamente la posibilidad de reemplazar la citología por la prueba de VPH en tamizaje primario. ${ }^{33-39}$

La baja especificidad de la prueba de VPH hace necesaria la aplicación de una segunda prueba de triaje para las mujeres que resulten VPH positivas. En países donde la citología es de buena calidad y los programas 
basados en ésta han tenido impacto en las tasas de cáncer de cuello uterino, la citología como prueba de triaje es una buena alternativa. La introducción del esquema combinado de VPH seguido de citología reducirá el número de citologías y, por ende, se incrementará el valor predictivo positivo de una citología alterada y es posible que se mejore el rendimiento de los citotecnólogos al tener un porcentaje mayor de citologías alteradas en su rutina diaria. ${ }^{40}$

El caso es distinto en países donde la citología cervical se ha utilizado de manera oportunista, sin lograr mayor cobertura y sin adecuado control de calidad o en regiones donde no se ha tamizado nunca por difícil acceso. Aquí la elección de la segunda prueba dependerá de la necesidad de reducir el número de visitas y de los recursos disponibles.

A continuación presentamos las experiencias más recientes del uso de la prueba de VPH en tamizaje primario y como triaje de citologías anormales en Latinoamérica.

VPH en muestra cervical. Estudio piloto poblacional en México

Un total de 50159 mujeres de 20-70 años de edad que acudieron a centros de tamizaje de diversos estados de México fueron tamizadas con citología convencional y la prueba de VPH (se usó captura de híbridos -Hybrid Capture II de QIAGEN HC2). ${ }^{28}$ Las mujeres con anormalidades citológicas (ASCUS+) fueron referidas a colposcopía independientemente del resultado de VPH. Las tasas de positividad globales fueron de 2.2\% (95\%IC: 2.0-2.3) para la citología y de 8.6\% (95\%IC: $8.3-$ 8.9) para la prueba de VPH. Adicionalmente, en el estado de Morelos se repitió el tamizaje un año más tarde a las mujeres VPH positivas que no presentaron anormalidades citológicas en el primer tamizaje, refiriéndose a colposcopía a las que resultaron VPH positivas o presentaron anormalidades citológicas en este segundo tamizaje. Al usar los resultados obtenidos en Morelos, se estimaron la sensibilidad y la especificidad para la detección de NIC2+ de 40\% (95\%IC: 38.5-41.4) y 97\% (95\%IC: 96.5-97.5) para la citología y de $93.3 \%$ (95\%IC: 92.5-94.0) y 89.2\% (95\%IC: 88.3-90.1) para la prueba de $\mathrm{VPH}$, respectivamente, confirmando una vez más el patrón ya observado mundialmente.

Autotoma de muestras vaginales para prueba de VPH en México. El estudio aleatorizado controlado $\mathrm{MARCH}$

En el estudio MARCH (acrónimo en inglés para Evaluación mexicana de tamizaje usando la prueba de VPH en muestras vaginales en comparación con la citología de rutina $)^{41}$ se aleatorizaron 22866 mujeres de 25-65 años, residentes en su mayoría de zonas rurales en México, a dos estrategias de tamizaje: a) brazo 1 ( $n=9$ 202): autotoma en casa de muestra vaginal para prueba de VPH (HC2), y, b) brazo 2 ( $n=13$ 664): citología de rutina en centros de salud. Las mujeres positivas a cualquiera de las dos pruebas fueron referidas a colposcopía. Al final del estudio, la prueba de VPH identificó 114.6/10,000 (93.2-136.0) NIC2+, casi tres veces más lesiones que la citología convencional que sólo identificó 38.95/10,000 (26.4-51.5). Este resultado ratifica la alta sensibilidad de la prueba de VPH, esta vez en muestras vaginales con el potencial de reducir una visita al servicio de salud, y por ende, el número de mujeres perdidas de vista y no tratadas oportunamente.

VPH en muestra cervical - Ensayo de campo en Santiago, Chile

En un estudio en curso en Santiago de Chile se está evaluando el desempeño de tres pruebas de tamizaje: a) detección del ADN del VPH en muestra cervical, b) IVAA y, c) citología convencional, en 10000 mujeres de 25-64 años que se atienden en tres centros de salud. ${ }^{42}$ La citología se procesa y lee en forma rutinaria. La detección del ADN del VPH se realiza en un laboratorio universitario de biología molecular usando HC2. El IVAA es realizado por enfermeras obstétricas luego de recolectar muestras cervicales para la citología convencional y la prueba de VPH. Se utilizan como criterios de positividad: para la citología la presencia de cualquier anormalidad (ASCUS+), para el IVAA la certera visualización de lesiones aceto-blancas evidentes en área de transformación y para la prueba de VPH una razón entre unidades relativas de luz y controles positivo de 1 o más (RLU/PC). Las mujeres con resultado positivo en cualquiera de las tres pruebas, además de un porcentaje de triples negativas, son referidas a colposcopía. A fin de evaluar la aceptabilidad y factibilidad del uso de la autotoma de muestra vaginal para la detección del $\mathrm{ADN}$ del VPH se añadió una rama de estudio donde se hacen visitas a domicilios y se ofrece el kit de autotoma a mujeres que no acuden al centro de salud a pesar de reiteradas invitaciones.

Desde agosto de 2009 a la fecha se han tamizado 8280 mujeres con las tres pruebas. Las tasas de positividad de cada prueba han sido $9.5 \%$ para la prueba de VPH, $1.9 \%$ para IVAAy $1.7 \%$ para la citología (ASCUS+). Alrededor de $8 \%$ de las mujeres tamizadas han sido referidas a colposcopía, identificándose 40 NIC2s, 31 NIC3s y 8 casos de cáncer invasor. La citología detectó $34.2 \%$ y la prueba de VPH $92.4 \%$ de todas las lesiones. 
La aceptabilidad de la autotoma por mujeres que no acuden a tamizaje fue alta. La prevalencia de NIC2 en este grupo fue de $1 \%$, contribuyendo con $14 \%$ de las lesiones detectadas por el programa de tamizaje. ${ }^{43}$

La prueba de VPH como prueba de triaje: estudio ASCUS en Medellín, Colombia

Este es un estudio que se inició recientemente en Medellín donde se espera aleatorizar 2868 mujeres con citología ASCUS, reclutadas a través de los laboratorios de los proveedores de servicios de salud (seguridad social y sistema público), a tres estrategias de manejo clínico: a) triaje con citología seguida de colposcopía si alguna citología a los seis y / o doce meses es ASCUS+, b) triaje y tratamiento inmediato con colposcopía, y, c) triaje con prueba de VPH seguida de colposcopía en VPH positivas; para determinar la eficacia de cada una de estas estrategias en reducir la prevalencia de NIC2+ luego de 2 años de seguimiento. Las mujeres con citología anormal o prueba VPH positiva son referidas a colposcopía y las mujeres diagnosticadas con $\mathrm{NIC} 2+$ tratadas. Luego de 24 meses desde su ingreso al estudio, las participantes tendrán una prueba de VPH y aquéllas que resulten VPH positivas serán referidas a colposcopía. Los datos de la fase piloto del estudio muestran que $50 \%$ de las mujeres en el brazo de VPH fueron positivas.

\section{Inspección visual directa como método de tamizaje primario}

La inspección visual directa (sin magnificación) con ácido acético (IVAA) o lugol (IVL) consiste en la aplicación de ácido acético a 5\% o lugol yodado en el cuello uterino, y la interpretación de resultados a partir de la observación de lesiones aceto-blancas o de zonas no captadoras del lugol respectivamente, que pueden ser tratadas inmediatamente. ${ }^{44}$ En varios estudios llevados a cabo en la región el IVAA ha mostrado una sensibilidad de al menos 50\% para la detección de NIC2 o lesiones mayores (NIC2+) (50.0\% en el estudio LAMS en Argentina y Brasil,$^{30} 54.9 \%$ el estudio TATI en Perú, ${ }^{27} 53.6 \%$ en un estudio en Colombia ${ }^{29}$ ), con excepción de México en donde la sensibilidad fue sólo $14.3 \% .{ }^{45}$ La variación en su rendimiento puede explicarse por la gran dependencia de esta prueba en la pericia del observador y por las diferencias importantes en los protocolos utilizados en cada estudio. Así, en Brasil el IVAA fue realizado por enfermeras y ginecólogos, en Perú por enfermeras profesionales especializadas en obstetricia, en Colombia por enfermeras, y en México únicamente por médicos.

Los estudios de Brasil y Colombia valoraron el uso de la inspección visual con lugol yodado (IVL), pero mientras en Brasil éste se evaluó de manera inde- pendiente, en Colombia se usó como complemento del IVAA. La sensibilidad del IVL fue mayor que la observada con el IVAA (Brasil 56.7\%, Colombia 68.1\%) pero la especificidad menor (77.9 y $90.8 \%$, respectivamente), resultados similares a los obtenidos en otras regiones del mundo. ${ }^{46}$

La inspección visual muestra una sensibilidad similar a la de la citología (ligeramente mayor para IVL) pero una menor especificidad. ${ }^{47}$ La utilidad de la técnica no radica entonces en su capacidad predictiva sino en: a) la posibilidad de ser realizada por personal de salud no médico y, b) la obtención de un resultado inmediato que permite ligarla al tratamiento en la misma visita; así, se facilita el acceso en regiones con difícil adherencia de las mujeres a un programa regular de tamizaje. En efecto, la alternativa de tamizar con IVAA y tratar sin métodos diagnósticos demostró una reducción de la mortalidad de $35 \%$ en seis años en un ensayo clínico realizado en la India. ${ }^{48}$ Sin embargo, este resultado no se repitió en un segundo estudio por el mismo grupo ${ }^{49}$ donde no se redujo la mortalidad con una única ronda de tamizaje con IVAA. Los autores no encontraron una explicación definitiva para esta discrepancia pero sugirieron que podía atribuirse a una tasa de tratamiento de mujeres IVAA positivas menor a la del primer estudio, que a su vez se puede asociar con una población blanco de menor riesgo y con menor incidencia de cáncer. ${ }^{29}$ Aún con estos resultados contradictorios, el IVAA ofrece un resultado inmediato y se puede incorporar en esquemas de tamizar y tratar con crioterapia, esquema que puede producir una disminución significativa del número de mujeres que no retornan al servicio de salud y no son tratadas oportunamente. Pero también hay que considerar el posible incremento de la tasa de sobretratamiento, especialmente en mujeres en edad fértil, asociado a la baja especificidad del IVAA.

También es claro que la crioterapia tiene una tasa de complicaciones menor de $1 \%,{ }^{48}$ esto sugiere que a pesar de sus limitaciones, el esquema IVAA-crioterapia podría ser útil en zonas con muy escasos recursos o con difícil acceso a servicios de salud, escenarios donde el rendimiento de la prueba y el beneficio del tratamiento rápido alcanzan su máximo potencial. ${ }^{29}$

\section{Desafíos para implementar las nuevas técnicas de tamizaje en América Latina}

\section{Incorporación de la prueba de VPH}

Varias técnicas de detección del ADN de VPHs de alto riesgo están siendo desarrolladas y validadas por compañías alrededor del mundo. La introducción de las pruebas de VPH en la práctica ginecológica requie- 
re el uso de ensayos bien validados. ${ }^{50}$ La prueba de ADN de VPH, HC2 ha sido ampliamente evaluada y ha demostrado consistente reproducibilidad de sus resultados entre laboratorios de diverso nivel de complejidad. Existe además la prueba careHPV, basada en la misma técnica, especialmente diseñada para permitir su implementación en áreas de escasos recursos y en zonas con difícil acceso a servicios de salud. Esta prueba proporciona resultados en menos de tres horas, es fácil de ejecutar, requiere una infraestructura mínima y ha mostrado una sensibilidad mayor a la de la citología e IVAA pero ligeramente menor que la prueba HC2. ${ }^{51}$ La disponibilidad de estas pruebas no descalifica otras técnicas aún en evaluación, que en su debido momento pueden convertirse en opciones competitivas y, por ende, ayudarán a la introducción masiva de esta tecnología en la región.

En zonas de buen desarrollo donde existen laboratorios preparados en cuanto a infraestructura, control de calidad y sistemas de procedimientos operativos estandarizados, se puede utilizar HC2, y en zonas de menos desarrollo será necesario utilizar careHPV u otra técnica alternativa. La prueba de HC2 se puede automatizar si el número de pruebas a realizarse por año es muy alto, al usar robots que pueden realizar entre 700 y 2000 pruebas al día dependiendo de la disponibilidad de personal para vigilar el proceso y del tipo de sistema que se utilice. En el estudio TATI en la Amazonía peruana y en los de México, la calidad de las muestras cervicales recolectadas no resultó afectada por exposición a temperaturas por encima de $30^{\circ} \mathrm{C}$ (máxima temperatura recomendada por el fabricante), y se confirmó que no se requiere cadena de frío y que, por lo tanto, las muestras se pueden transportar fácilmente sin detrimento de la calidad de la prueba lo que hace posible su centralización en pocos laboratorios.

Es evidente que al usar la prueba de VPH se detectan más casos de lesiones pre-cancerosas del cuello del útero que con la citología tradicional. Los estudios descritos anteriormente coincidieron en al menos cuatro puntos:

1. La aceptabilidad y factibilidad del uso de la prueba por el personal encargado de toma de muestra cervical, luego de un entrenamiento corto

2. La aceptabilidad y factibilidad de la autotoma de muestras vaginales por mujeres visitadas en casa

3. La factibilidad de utilizar la prueba a nivel poblacional haciendo uso de la infraestructura y recursos ya disponibles dentro de un programa de tamizaje cervical
4. El incremento del número de mujeres referidas a colposcopía a consecuencia de un resultado VPH positivo

Este último punto representa el gran desafío para la implementación de la prueba en tamizaje primario. Tanto en el estudio de Chile como en los de México, el número de citas en los servicios de colposcopía se incrementó significativamente; en Chile, se tuvieron que organizar servicios adicionales a fin de evitar retrasos en la atención, mientras que en México se usaron distintas estrategias para no perder de vista a mujeres cuya evaluación colposcópica tuvo que ser pospuesta varias semanas. Este retraso puede representar un problema serio para un programa de tamizaje, pues las demoras en la atención al igual que el aumento del número de visitas al servicio de salud incrementan la posibilidad de pérdida de mujeres positivas antes de completar tratamiento.

Se hace entonces imprescindible el uso de una prueba de triaje que acompañe a la prueba de VPH a fin de evitar la sobrecarga de los servicios de colposcopía. La pregunta de cuál sería esta segunda prueba aún no ha sido respondida y es evidente que no tiene una única respuesta, sino que su elección dependerá de los recursos con que cuente cada escenario y de la disponibilidad de nuevas pruebas moleculares en el futuro.

Se espera que la prueba de VPH sea utilizada en tamizaje primario, triaje para selección de tratamiento, seguimiento de mujeres tratadas y más adelante como estrategia de vigilancia de mujeres vacunadas contra la infección. Por esto es necesario que las técnicas de detección del ADN del VPH se incorporen en el entrenamiento de tecnólogos y que se promueva la centralización de laboratorios con rigurosos estándares de calidad, a fin de preparar la plataforma para el cambio. Pero además se requiere de un enorme esfuerzo en la formación de los profesionales de la salud en el uso e interpretación de los resultados de las pruebas de VPH, para que la introducción de la prueba no genere mayor ansiedad en la población.

\section{Incorporación del IVAA en tamizaje primario}

Las técnicas visuales han sido utilizadas en varios estudios en la región, pero el IVAA solamente ha sido incorporado como técnica de tamizaje dentro de los programas de prevención de cáncer de cuello uterino de Perú y de Nicaragua donde actualmente están trabajando en su implementación dentro del sistema de atención primaria. 
El costo de la prueba es mínimo. El principal desafío consiste en establecer un buen sistema de entrenamiento, monitoreo y certificación de proveedores, $\mathrm{y}$ en establecer esquemas de tratamiento que aprovechen de mejor manera la disponibilidad del resultado inmediato del IVAA. Por ejemplo, el Instituto de Enfermedades Neoplásicas (INEN) de Perú, PATH (Seattle, USA) y JHPiego (Baltimore, USA), junto con otras instituciones nacionales e internacionales, han creado un centro de excelencia para entrenamiento (estandarizado) y certificación de proveedores y futuros entrenadores de IVAA.

Debido a las limitaciones de la técnica, es importante enfatizar que el uso de IVAA debe ser restringido a grupos de elevado riesgo de cáncer con difícil acceso a los servicios de salud. De otra parte, se ha sugerido que la sensibilidad de las técnicas de inspección visual reportada por estudios de corte transversal puede estar sobreestimada debido a su alta correlación con la colposcopía la cual se usa como estándar de confirmación diagnóstica. Los ensayos clínicos muestran que una elevada sensibilidad asegura un mayor impacto en la reducción de la mortalidad si se espera un número reducido de contactos con las mujeres y, en esa medida, la posibilidad de contar con pruebas de VPH con resultado inmediato que posibiliten el tratamiento en la misma visita sería una mejor alternativa para estas poblaciones en el futuro.

\section{Recomendaciones para la implementación de sistemas de tamizaje de lesiones cervicouterinas}

La implementación de un programa de detección temprana de lesiones precancerosas de cuello uterino no tiene ningún impacto si no se acompaña de un sistema adecuado para la evaluación de los casos que resulten positivos, además de recursos para asegurar el tratamiento de los casos que lo requieran. Así, antes de introducir la prueba de VPH o el IVAA en un programa de tamizaje masivo se deben definir claramente la población objetivo y los esquemas de triaje de casos positivos, de diagnóstico y tratamiento de lesiones detectadas.

\section{Edad de tamizaje}

No existen evaluaciones del impacto del tamizaje en diferentes grupos de edad en poblaciones latinoamericanas, e históricamente, la elección de la edad de tamizaje se ha decidido con base en la edad promedio de inicio de relaciones sexuales o a las recomendaciones adoptadas en otros países. Actualmente, la edad de inicio de tamizaje con citología varía entre 20 y 35 años en la región.
Consideramos que el inicio del tamizaje no debe ser antes de los 30 años, por las siguientes razones:

1. La tasa de positividad de cualquier prueba de tamizaje, sea esta VPH, IVAA o citología, es elevada en mujeres jóvenes debido a la mayor prevalencia de la infección por VPH

2. La alta prevalencia de la infección por VPH en mujeres menores de 30 años se traduce en una alta tasa de lesiones de bajo grado que usualmente desaparecen en el término de dos años y no representan un riesgo de cáncer

3. La tasa de incidencia de cáncer de cuello uterino en mujeres menores de 30 años es muy baja

4. El tamizaje en mujeres muy jóvenes no es efectivo. Una evaluación reciente del programa de tamizaje cervical de Inglaterra, basado en citología, encontró que el programa reduce la incidencia de cáncer en $60-80 \%$ en mujeres entre 40 y 64 años, pero que no tiene ningún impacto el tamizaje de mujeres menores de 25 años. ${ }^{52}$

Proponemos entonces que el tamizaje se debefocalizar en mujeres de 30 a 59 años. Si los recursos son insuficientes para tamizar a todo este grupo, se debe dar prioridad a mujeres entre 30 y 49 años. Si se dispone de más recursos y principalmente si se observa poca adherencia en mujeres de 50 a 59 años (uno o cero tamizajes en esa edad) se recomienda extender el tamizaje por lo menos hasta los 64 años, y asegurar que la mayoría de las mujeres sobre los 50 años tengan al menos dos tamizajes en su vida adulta. Para programas basados en IVAA, debido a la pérdida de efectividad de la prueba en mujeres mayores de 49 años por cambios fisiológicos asociados a la menopausia, recomendamos restringir el tamizaje a mujeres de 30 a 49 años y esperar a que careHPV u otras técnicas más adecuadas para escenarios difíciles o con menos recursos se puedan aplicar a mujeres mayores de 49 años.

\section{Intervalo de tamizaje}

El intervalo de tamizaje dependerá del valor predictivo negativo de la prueba en uso. En este sentido es claro proponer un intervalo de cinco años entre cada prueba de VPH y de tres años tanto para citología como IVAA. Estudios recientes han mostrado que el riesgo de desarrollar precáncer o cáncer de cuello uterino luego de una prueba VPH negativa es casi nulo hasta seis años más tarde. ${ }^{33,53-56}$ Esta información podría permitir la extensión del periodo entre cada tamizaje a cinco años. Además, se espera que nuevas evaluaciones de estudios longitudinales demuestren que la protección continúa por más años, lo que hace posible que en el futuro el 
intervalo de tamizaje se pueda extender quizás hasta 10 años, especialmente en mujeres con dos pruebas VPH negativas anteriores. ${ }^{56}$ Esta extensión del intervalo reduciría el número de pruebas de tamizaje por año y el número de tamizajes que una mujer tendría en su vida. Por ejemplo, consideremos un escenario hipotético donde se requiera tamizar a 100000 mujeres de 30-59 años cada 3 años (trienal). En 10 años se harían por lo menos 1 millón de pruebas, mientras que con un intervalo quinquenal (cada 5 años) sólo se harían 600 000, y en uno decenal (cada 10 años) tan sólo 300 000. Similarmente, con el esquema trienal las mujeres tendrían diez tamizajes, con el quinquenal sólo seis y con el decenal tan sólo tres. Asumiendo adecuada adherencia al programa, la extensión del intervalo reduciría significativamente la ansiedad generada en las mujeres de la población objetivo y el costo de implementación del programa en el largo plazo, sin perder efectividad para la prevención de cáncer de cuello uterino.

\section{Prueba de triaje}

Una de las preguntas a resolver cuando se usa la prueba de VPH como primera prueba (tamizaje primario) es el rol de una segunda prueba aplicada sólo a las mujeres que resulten VPH positivas, con el fin de reducir el número de referencias a colposcopía y evitar el posible sobretratamiento. En la mayoría de los países de la región la citología no es una opción. Actualmente se están evaluando técnicas alternativas como la tipificación de VPH 16 y 18, la citología con inmuno-histoquímica de p16 (citología-p16), la expresión de E6/E7 (mRNA E6/ E7), ${ }^{57}$ y quizás la referencia a colposcopía de mujeres sobre los 35 años en quienes la tasa de positividad de la prueba de VPH es menor y la especificidad mayor. En cualquiera de los casos, la introducción de una prueba de triaje podría implicar un incremento en el número de visitas para las mujeres VPH positivas y como consecuencia, tal y como se anotó anteriormente, la pérdida de mujeres positivas antes del tratamiento.

\section{Diagnóstico y tratamiento de lesiones detectadas}

El manejo convencional de lesiones detectadas incluye la valoración colposcópica, la confirmación del diagnóstico mediante biopsia y el tratamiento de lesiones precancerosas usualmente con asa electroquirúrgica. Sin embargo, el protocolo de manejo clínico dependerá de los recursos disponibles en cada escenario, por este motivo es importante realizar un diagnóstico situacional adecuado antes de empezar un programa de tamizaje. Si los recursos son limitados y no se cuenta con la certeza de que una biopsia va a ser leída y reportada a tiempo y con alta calidad, entonces se deben evaluar mecanismos alternativos para impedir retrasos en el tratamiento de mujeres a las que se les detectan lesiones. Una alternativa es proporcionar tratamiento con crioterapia basado sólo en la evaluación directa del cuello uterino para descartar la presencia de cáncer invasor. Bajo esta estrategia, toda mujer con tamizaje positivo es evaluada con IVAA y es referida a un nivel más especializado si hay sospecha de cáncer invasor o si la lesión aceto-blanca es muy extensa y no es elegible para crioterapia. Pero si la mujer es elegible para recibir crioterapia, entonces este tratamiento debe ser proporcionado en el nivel primario del sistema de atención de salud. El principal problema de esta estrategia es la resistencia de los médicos a tratar mujeres sin diagnóstico histológico de la enfermedad o sin tener la certeza de que la mujer no tiene cáncer invasor; pero debe considerarse cuidadosamente el beneficio de que las mujeres sean tratadas a tiempo sobre el requerimiento de colposcopía y biopsia para tomar esta decisión.

En áreas con mejores recursos donde se puedan realizar biopsias y reportes histológicos a tiempo, usualmente el factor limitante es el contar con acceso adecuado a evaluación de colposcopía para dirigir la toma de biopsias pues el número de médicos entrenados para realizarla es limitado y no se cuenta con suficientes equipos colposcópicos. Se han propuesto diversas estrategias para aumentar el acceso a evaluación magnificada del cuello uterino; una posibilidad es el uso de cámaras fotográficas digitales con adecuado zoom óptico. Esta alternativa también abre la posibilidad del uso del Internet para compartir las imágenes con centros especializados para consulta por especialistas.

Se recomienda que en cualquier escenario donde se realicen colposcopías se cuente con protocolos estándares del procedimiento y del reporte de sus resultados, y que se evalúe el desempeño de los servicios regularmente. La factibilidad del uso compartido de imágenes vía Internet se presenta como una alternativa para garantizar la calidad del examen. En resumen:

\section{Uso de la prueba de VPH}

Se cuenta con dos pruebas hasta el momento: a) HC2, indicada para lugares que cuenten con laboratorios de biología molecular y para lugares con mucha densidad poblacional o donde se pueda centralizar la prueba en un número mínimo adecuado de laboratorios, y próximamente con b) careHPV, indicada para lugares donde no existen laboratorios o éstos son muy básicos y limitados, o para zonas con baja densidad poblacional o donde se trabaje la población mediante campañas de salud. Estas pruebas deberán complementarse con 
una segunda prueba de triaje adecuada dentro de un esquema de tamizaje que garantice el funcionamiento regular del sistema y el mayor número de mujeres tratadas oportunamente.

\section{Uso del IVAA}

Para escenarios de escasos recursos, con ningún tipo de acceso a servicios de salud o donde quizás sólo se visite a la población en muy pocas ocasiones debido a grandes dificultades geográficas, se recomienda usar el IVAA como única prueba seguida de tratamiento inmediato con crioterapia. Comprendiendo que la prueba tiene un costo mínimo, en algunos casos se optará por utilizar IVAA en un escenario con acceso a laboratorios de histopatología; bajo este escenario se sugiere tomar una biopsia antes del tratamiento. Para implementar IVAA debe certificarse y entrenarse constantemente al personal de salud que realice el examen y enfatizarse que mujeres con lesiones no elegibles para crioterapia o con sospecha de cáncer deben ser inmediatamente referidas al hospital competente.

El cuadro II resume nuestras recomendaciones para la introducción de la prueba del VPH y del IVAA.

\section{Vacunas contra la infección por VPH. Una perspectiva de salud pública}

Actualmente están disponibles comercialmente dos vacunas para la profilaxis de las infecciones por VPH:58 una vacuna bivalente, con dos proteínas antigénicas no infecciosas de VPH 16 y 18 (Cervarix), y una vacuna tetravalente, con cuatro proteínas antigénicas de VPH 16,
18, 6 y 11 (Gardasil); los dos últimos tipos proporcionan prevención de verrugas genitales y/o papilomatosis respiratoria recurrente.

De acuerdo con los hallazgos de ensayos clínicos desarrollados en más de 40 áreas geográficas a nivel mundial, ${ }^{59-61}$ ambas vacunas ofrecen un excelente perfil de eficacia y seguridad:62-64

1. Eficacia cercana a $100 \%$ para la prevención de lesiones relacionadas a VPH 16-18 en mujeres no expuestas previamente a VPH,

2. Buena persistencia de anticuerpos durante siete años, ${ }^{65} \mathrm{y}$,

3. Aceptable perfil de seguridad. ${ }^{66}$

En mujeres con infección por VPH 16 o VPH18, la aplicación de vacunas no ha evidenciado un efecto terapéutico, ${ }^{67}$ aunque también mujeres con seropositividad a VPH 16 y 18 en ausencia de infección por VPH (ADN de VPH negativo) pueden beneficiarse con el uso de la vacuna. ${ }^{68}$ Sin embargo, para lograr el máximo costobeneficio, los programas de vacunación deben enfocarse en mujeres adolescentes que aún no se han expuesto a estos virus.

Existen nuevos desarrollos tecnológicos con nuevas generaciones de vacunas polivalentes contra VPH, que incluirán una protección contra nueve genotipos. ${ }^{69}$

El costo actual de las vacunas hace inviable su promoción poblacional en países pobres y de ingresos medios. Ala fecha la mayoría de los países desarrollados han iniciado programas de vacunación universal en niñas adolescentes, pero muy pocos países de América Latina los han iniciado. Los escasos recursos públicos

\section{Cuadro II}

\section{Posibles esquemas de tamizaje USANDO diferentes PRUebas PRIMARIAS}

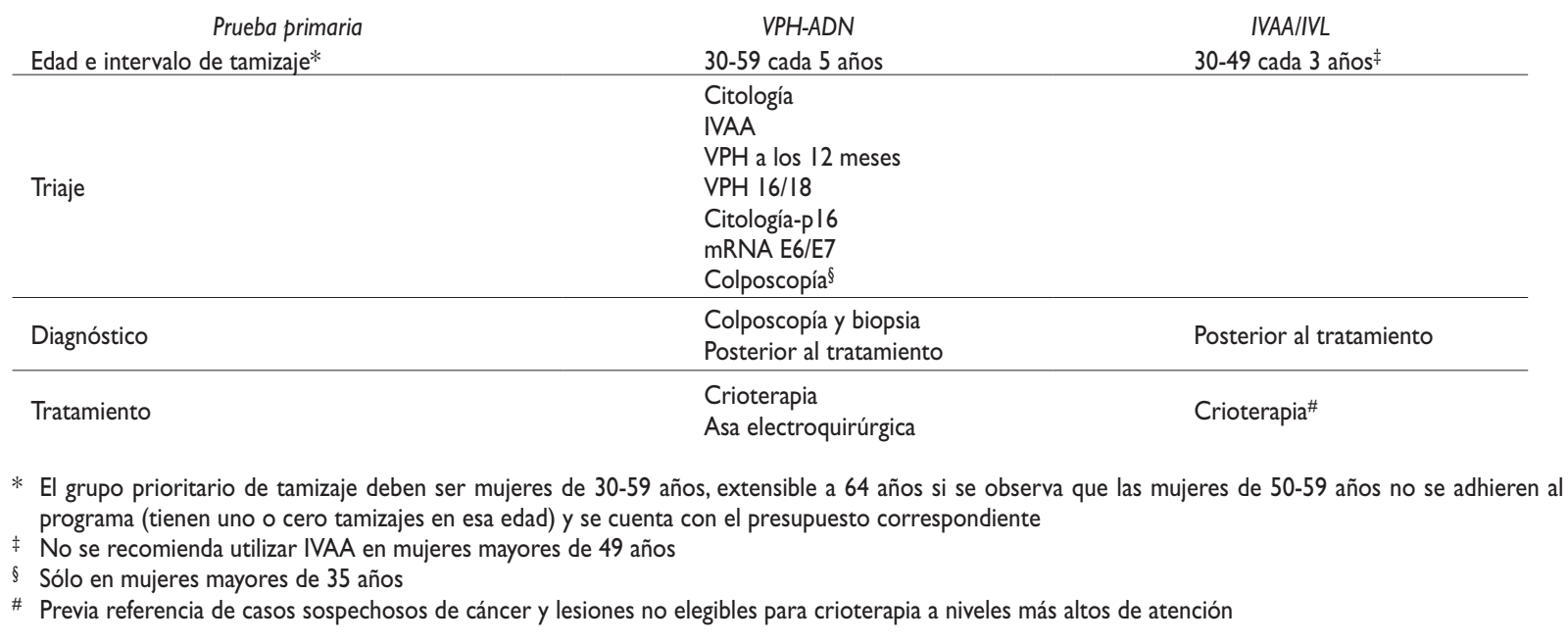


utilizados en la prevención y control del cáncer de cuello uterino deberán ser maximizados para obtener el mayor beneficio. Actualmente existen diversas intervenciones de prevención primaria con vacunas contra VPH que deberán considerarse para promover la equidad, particularmente en la región de Latinoamérica.

En los estudios de inmunogenicidad de vacunas contra VPH, es consistente la observación de un mayor pico de anticuerpos en el séptimo mes del inicio de la vacunación. ${ }^{66}$ Posteriormente, se produce un descenso paulatino de los niveles de anticuerpos, y al llegar al mes 24 se estabilizan y se mantienen constantes hasta el mes $60 .^{70}$

A la fecha no se conoce el nivel mínimo de anticuerpos que se correlacione con protección clínica; lo que se ha establecido es la correlación entre presencia de anticuerpos y el efecto profiláctico. Sin embargo, se ha observado que en mujeres de 10 a 17 años de edad, los títulos medios geométricos de IgG (GMTs) son al menos dos veces más elevados que en mujeres de 15 a 25 años. ${ }^{71}$ Adicionalmente, la respuesta inmunológica de las niñas de 9 a 11 años después de dos dosis de vacuna es similar o mayor a la obtenida después de tres dosis en mujeres de 16 a 26 años de edad, en quienes se ha probado la eficacia de la vacuna. ${ }^{65,72}$

En sujetos vacunados con el esquema normal, la aplicación de una dosis extra (cuarta dosis) de vacuna a los 60 meses de la primera vacunación muestra una rápida y vigorosa respuesta inmunitaria de memoria frente a los cuatro tipos de VPH incluidos en la vacuna, que excede los niveles de GMTs observados al séptimo mes de iniciada la vacunación, ${ }^{73}$ respuesta similar a la observada con la vacuna contra la hepatitis B. ${ }^{67,74}$

Con estos antecedentes, algunos grupos en México y Canadá han propuesto que el empleo de un esquema extendido de vacunación, esto es, un esquema inicial con dos dosis ( 0 y 2 meses ó 0 y 6 meses) y una tercera a los 60 meses, en niñas de 9-10 años, puede ofrecer: a) mejoras en la respuesta inmune a mediano y largo plazo, además de ofrecer la máxima protección alrededor del inicio de relaciones sexuales, $y, b$ ) ventajas en su administración, ya que es más sencilla la organización de estos esquemas en el marco de las escuelas, y en consecuencia, una mejor oportunidad de equidad al poder obtener una mayor cobertura y adherencia a esquemas completos en población cautiva antes de abandonar la escuela obligatoria.

A comienzos de este año se inició un estudio a gran escala para evaluar la equivalencia, en términos de respuesta inmunológica, de un esquema de dos dosis $(0$, 12 meses) en comparación con tres dosis ( $0,2,6$ meses) en varias regiones de la India.

Asimismo, la Comisión Nacional de Inmunizaciones (NACI) de Canadá ha iniciado una evaluación cuidadosa de un esquema de vacunación ampliado: 0, 2 y 60 meses mediante una intervención en tres provincias de Canadá. ${ }^{75}$ Esta evaluación incluye la posibilidad de no ofrecer la tercera dosis en caso de que los niveles de inmunogenicidad a los 60 meses así lo permitan.

La recomendación sobre vacunación contra VPH en instituciones de salud pública en México es la de iniciar, en la medida de lo posible, la cobertura de prevención primaria en niñas entre 9 y 11 años, con un esquema de vacunación contra VPH a los 0,6 y 60 meses. ${ }^{76}$ Este programa ha comenzado en escuelas públicas de la Ciudad de México por parte del Gobierno del Distrito Federal, y en municipios de alta marginalidad en distintas regiones del país, por parte de los servicios médicos del gobierno federal, y se ha considerado que una rigurosa evaluación del esquema ampliado de vacunación deberá llevarse a cabo en cada región.

Las evaluaciones de distintos esquemas de vacunación y distintas estrategias de aplicación conjunta con otras vacunas en adolescentes podrían sustentar la reducción de los esquemas a dos o a una dosis, lo que facilita la introducción de la vacunación universal contra la infección por VPH en países de la región.

\section{Conclusiones}

El cáncer de cuello uterino continúa siendo un problema de salud pública en la región. En vista de que el tamizaje con citología no ha tenido impacto en las tasas de incidencia y mortalidad, se hace inminente la adopción de nuevas estrategias de tamizaje y la incorporación de programas de vacunación contra la infección de VPH en niñas adolescentes. La potencial reducción del precio tanto de las vacunas disponibles actualmente como de las pruebas del ADN del VPH -especialmente si se utilizan en forma masiva- ofrece una nueva perspectiva para la prevención.

Cada país deberá hacer un análisis situacional de su población identificando escenarios con distintos niveles de recursos y accesibilidad para formular (o mejorar) programas de prevención que hagan uso óptimo de la capacidad instalada y los recursos humanos disponibles.

\section{Declaración de conflicto de intereses}

Raúl Murillo ha asistido a reuniones de consultoría y congresos de MSD y GSK. Eduardo Lazcano Ponce ha recibido financiamiento de Glaxo y Merck para desarrollo de ensayos clínicos de vacunas contra VPH, y donación de reactivos de Digene, Qiagem y Roche para identificar $\mathrm{ADN}$ de VPH. Los restantes autores declaran no tener conflicto de intereses. 


\section{Referencias}

I. Sasieni P,Adams J. Effect of screening on cervical cancer mortality in England and Wales: analysis of trends with an age period cohort model. Bmj 1999;3 I8(7I93):I244-I 245.

2. Hakama M, Louhivuori K.A screening programme for cervical cancer that worked. Cancer Surv 1988;7(3):403-416.

3.Arbyn M, Rebolj M, De Kok IM, Fender M, Becker N, O'Reilly M, et al. The challenges of organising cervical screening programmes in the 15 old member states of the European Union. Eur J Cancer 2009;45(I5): $267 \mid-2678$.

4. Ferlay J, Bray F, Pisani P, Parkin D. GLOBOCAN 2002. Cancer Incidence, Mortality and Prevalence Worldwide. IARC CancerBase No 5 version 2.0 2004.

5. Cuzick J, Clavel C, Petry KU, Meijer CJ, Hoyer H, Ratnam S, et al.

Overview of the European and North American studies on HPV testing in primary cervical cancer screening. Int J Cancer 2006; I 19(5): 1095- I I0 I. 6. Muñoz N, Bosch FX, de Sanjose S, Herrero R, Castellsague X, Shah KV, et al. Epidemiologic classification of human papillomavirus types associated with cervical cancer. N EngI J Med 2003;348(6):5 I8-527.

7.Walboomers JM, Jacobs MV, Manos MM, Bosch FX, Kummer JA, Shah $\mathrm{KV}$, et al. Human papillomavirus is a necessary cause of invasive cervical cancer worldwide.J Pathol 1999;189(I):12-19.

8. Ferlay J, Shin H, Bray F, Forman D, Mathers C, Parkin DM. GLOBOCAN 2008, Cancer Incidence and Mortality Worldwide: IARC CancerBase No. 10 [Internet]. Lyon, France: International Agency for Research on Cancer, 2010. Available at: http://globocan.iarc.fr, 2010.

9. Yang BH, Bray FI, Parkin DM, Sellors JW, Zhang ZF. Cervical cancer as a priority for prevention in different world regions: an evaluation using years of life lost. Int J Cancer 2004;109(3):418-424.

10. Parkin DM,Almonte M, Bruni L, Clifford G, Curado MP, Pineros M. Burden and trends of type-specific human papillomavirus infections and related diseases in the Latin America and Caribbean region.Vaccine 2008;26 Suppl II:LI-I5.

II. Palacio-Mejía LS, Rancel-Gómez G, Hernández-Avila M, Lazcano-Ponce E. Cervical cancer; a disease of poverty: Mortality differences between urban and rural areas in Mexico. Salud Publica Mex 2003;45(3):S3I5-S325. 12. Einstein MH, Schiller JT,Viscidi RP, Strickler HD, Coursaget P,Tan T, et al. Clinician's guide to human papillomavirus immunology: knowns and unknowns. Lancet Infect Dis 2009;9(6):347-356.

13. Schiffman M, Herrero R, Desalle R, Hildesheim A, Wacholder S, Rodriguez AC, et al. The carcinogenicity of human papillomavirus types reflects viral evolution.Virology 2005;337(I):76-84.

14. Porras C, Rodriguez AC, Hildesheim A, Herrero R, Gonzalez P,

Wacholder $S$, et al. Human papillomavirus types by age in cervical cancer precursors: predominance of human papillomavirus 16 in young women. Cancer Epidemiol Biomarkers Prev 2009; 18(3):863-865.

15. Khan MJ, Castle PE, Lorincz AT, Wacholder S, Sherman M, Scott DR, et al. The elevated I0-year risk of cervical precancer and cancer in women with human papillomavirus (HPV) type 16 or 18 and the possible utility of type-specific HPV testing in clinical practice. J Natl Cancer Inst 2005;97(14): 1072-1079.

16. Castellsague X, Diaz M, de Sanjose S, Muñoz N, Herrero R, Franceschi $S$, et al.Worldwide human papillomavirus etiology of cervical adenocarcinoma and its cofactors: implications for screening and prevention.J Natl Cancer Inst 2006;98(5):303-315.

17. Rodriguez AC, Schiffman M, Herrero R, Wacholder S, Hildesheim $A$, Castle PE, et al. Rapid clearance of human papillomavirus and implications for clinical focus on persistent infections. J Natl Cancer Inst 2008;100(7):513-517.

18. Schiffman M, Castle PE, Jeronimo J, Rodriguez AC, Wacholder S. Human papillomavirus and cervical cancer. Lancet 2007;370(9590):890-907.
19. McCredie MR, Sharples KJ, Paul C, Baranyai J, Medley G, Jones RW, et al. Natural history of cervical neoplasia and risk of invasive cancer in women with cervical intraepithelial neoplasia 3: a retrospective cohort study. Lancet Oncol 2008;9(5):425-434.

20. Carreon JD, Sherman ME, Guillen D, Solomon D, Herrero R, Jeronimo J, et al. CIN2 is a much less reproducible and less valid diagnosis than CIN3: results from a histological review of population-based cervical samples. Int J Gynecol Pathol 2007;26(4):44I-446.

21. Solomon D, Davey D, Kurman R, Moriarty A, O'Connor D, Prey M, et al.The 200I Bethesda System: terminology for reporting results of cervical cytology. Jama 2002;287(|6):2| |4-2| |9.

22. Herrero R, Castle PE, Schiffman M, Bratti MC, Hildesheim A, Morales J, et al. Epidemiologic profile of type-specific human papillomavirus infection and cervical neoplasia in Guanacaste, Costa Rica.J Infect Dis 2005;19|(II):1796-1807.

23. Lazcano-Ponce E, Herrero R, Muñoz N, Cruz A, Shah KV, Alonso P, et al. Epidemiology of HPV infection among Mexican women with normal cervical cytology. Int J Cancer 200 I;9I(3):412-420.

24. Ferreccio C, Prado RB, Luzoro AV,Ampuero SL, Snijders PJ, Meijer $\mathrm{CJ}$, et al. Population-based prevalence and age distribution of human papillomavirus among women in Santiago, Chile. Cancer Epidemiol Biomarkers Prev 2004;I3(I2):227I-2276.

25. Molano M, Posso H,Weiderpass E, van den Brule AJ, Ronderos M, Franceschi $S$, et al. Prevalence and determinants of HPV infection among Colombian women with normal cytology. Br J Cancer 2002;87(3):324-333. 26. Garcia-Pineres AJ, Hildesheim A, Herrero R, Trivett M,Williams M, Atmetlla I, et al. Persistent human papillomavirus infection is associated with a generalized decrease in immune responsiveness in older women. Cancer Res 2006;66(22): I 1070-1 1076.

27. Almonte M, Ferreccio C,Winkler JL, Cuzick J,Tsu V, Robles S, et al. Cervical screening by visual inspection, HPV testing, liquid-based and conventional cytology in Amazonian Peru. Int J Cancer 2007; I2I (4):796-802. 28. Lazcano-Ponce E, Lorincz AT, Salmeron J, Fernandez I, Cruz A, Hernandez P, et al.A pilot study of HPV DNA and cytology testing in 50,159 women in the routine Mexican Social Security Program. Cancer Causes Control 2010:21(10):1693-1700.

29. Murillo R, Luna J, Gamboa O, Osorio E, Bonilla J, Cendales R. Cervical cancer screening with naked-eye visual inspection in Colombia. Int J Gynaecol Obstet 2010;109(3):230-234.

30. Sarian LO, Derchain SF, Naud P, Roteli-Martins C, Longatto-Filho A, Tatti S, et al. Evaluation of visual inspection with acetic acid (VIA), Lugol's iodine (VILI), cervical cytology and HPV testing as cervical screening tools in Latin America. This report refers to partial results from the LAMS (Latin AMerican Screening) study.J Med Screen 2005; I2(3): 142-149. 3I. Ferreccio C, Bratti MC, Sherman ME, Herrero R, Wacholder S, Hildesheim A, et al.A comparison of single and combined visual, cytologic, and virologic tests as screening strategies in a region at high risk of cervical cancer. Cancer Epidemiol Biomarkers Prev 2003;12(9):815-823. 32. Smith RA, Cokkinides V, Brooks D, Saslow D, Brawley OW. Cancer screening in the United States, 2010: a review of current American Cancer Society guidelines and issues in cancer screening. CA Cancer J Clin 2010;60(2):99-119.

33. Ronco G, Giorgi-Rossi P, Carozzi F, Confortini M, Dalla Palma P, Del Mistro A, et al. Efficacy of human papillomavirus testing for the detection of invasive cervical cancers and cervical intraepithelial neoplasia: a randomised controlled trial. Lancet Oncol 2010; I I(3):249-257. 34. Leinonen M, Nieminen P, Kotaniemi-Talonen L, Malila N,Tarkkanen J, Laurila P, et al.Age-specific evaluation of primary human papillomavirus screening vs conventional cytology in a randomized setting.J Natl Cancer Inst 2009;101(23): 1612-1623.

35. Bulkmans NW, Berkhof J, Rozendaal L, van Kemenade FJ, Boeke AJ, Bulk S, et al. Human papillomavirus DNA testing for the detection of cervical intraepithelial neoplasia grade 3 and cancer: 5 -year 
follow-up of a randomised controlled implementation trial. Lancet 2007;370(960I):1764-1772.

36. Naucler P, Ryd W, Tornberg S, Strand A, Wadell G, Elfgren K, et al. Efficacy of HPV DNA testing with cytology triage and/or repeat HPV DNA testing in primary cervical cancer screening.J Natl Cancer Inst 2009; 10I (2):88-99.

37. Naucler P, Ryd W, Tornberg S, Strand A, Wadell G, Elfgren K, et al. Human papillomavirus and Papanicolaou tests to screen for cervical cancer. N Engl J Med 2007;357(I6): I589-1597.

38. Kitchener HC,Almonte M,Thomson C, Wheeler P, Sargent A, Stoykova $B$, et al. HPV testing in combination with liquid-based cytology in primary cervical screening (ARTISTIC): a randomised controlled trial. Lancet Oncol 2009;10(7):672-682.

39. Mayrand MH, Duarte-Franco E, Rodrigues I,Walter SD, Hanley J, Ferenczy A, et al. Human papillomavirus DNA versus Papanicolaou screening tests for cervical cancer. N Engl J Med 2007;357(I6):I579-I588. 40. Franco EL,Tsu V, Herrero R, Lazcano-Ponce E, Hildesheim A, Muñoz N, et al. Integration of human papillomavirus vaccination and cervical cancer screening in Latin America and the Caribbean.Vaccine 2008;26 Suppl I I:L88-L95.

41. Lazcano-Ponce E, Lorincz AT, Cruz-Valdes A, Salmerón J, Uribe P, Velasco E, et al. Improving cervical cancer screening by HPV testing of vaginal specimens self-collected at home: the MARCH Randomised Controlled Trial.The Lancet Conferences. HPV and Cancer.Abstract 002; 2010;Amsterdam, the Netherlands.

42. Terrazas S, Poggi H, Cook P, Barriiga M, Santyana P, Ibáñez C, et al. Field trial of screening options for cervical cancer in Chile: preliminary results. 26th International Papillomavirus Conference. Abstract P-524; 2010; Monteal, Canada.

43. Barriga M, Ibáñez C, González F, Terrazas S, Lagos M, Ferreccio C. Ensayo de campo del ADN deVPH y del Papanicolaou en la detección precoz del cáncer de cuello uterino. Santiago de Chile 2009-2010. Congreso de Salud Pública Chileno; 2010; Chile.

44. Sankaranarayanan R,Wesley R.A practical manual on visual screening for cervical neoplasia. IARC Technical Publication No.4I. Lyon: IARC, 2003. 45. Perez-Cruz E,Winkler JL,Velasco-Mondragon E, Salmeron-Castro J, Garcia F, Davis-Tsu V, et al. [Screening and follow-up for cervical cancer prevention in rural Mexico using visual inspection]. Salud Publica Mex 2005;47(I):39-48.

46. Shastri SS, Dinshaw K,Amin G, Goswami S, Patil S, Chinoy R, et al. Concurrent evaluation of visual, cytological and HPV testing as screening methods for the early detection of cervical neoplasia in Mumbai, India. BullWorld Health Organ 2005;83(3): 186-194.

47. Cuzick J,Arbyn M, Sankaranarayanan R, Tsu V, Ronco G, Mayrand MH, et al. Overview of human papillomavirus-based and other novel options for cervical cancer screening in developed and developing countries. Vaccine 2008;26 Suppl I0:K29-K4I.

48. Sankaranarayanan R, Esmy PO, Rajkumar R, Muwonge R, Swaminathan $R$, Shanthakumari $S$, et al. Effect of visual screening on cervical cancer incidence and mortality in Tamil Nadu, India: a cluster-randomised trial. Lancet 2007;370(9585):398-406.

49. Sankaranarayanan R, Nene BM, Shastri SS, Jayant K, Muwonge R, Budukh AM, et al. HPV screening for cervical cancer in rural India. N Engl J Med 2009;360(I4):1385-1394.

50. Stoler MH, Castle PE, Solomon D, Schiffman M. The expanded use of HPV testing in gynecologic practice per ASCCP-guided management requires the use of well-validated assays. Am J Clin Pathol 2007; I27(3):335-337.

51. Qiao YL, Sellors JW, Eder PS, Bao YP, Lim JM, Zhao FH, et al.A new HPV-DNA test for cervical-cancer screening in developing regions: a cross-sectional study of clinical accuracy in rural China. Lancet Oncol 2008;9(10):929-936.
52. Sasieni P, Castanon A, Cuzick J. Effectiveness of cervical screening with age: population based case-control study of prospectively recorded data. BMJ 2009;339:b2968.

53. Sherman ME, Lorincz AT, Scott DR, Wacholder S, Castle PE, Glass AG, et al. Baseline cytology, human papillomavirus testing, and risk for cervical neoplasia: a I0-year cohort analysis. J Natl Cancer Inst 2003;95(I):46-52. 54. Dillner J, Rebolj M, Birembaut P, Petry KU, Szarewski A, Munk C, et al. Long term predictive values of cytology and human papillomavirus testing in cervical cancer screening: joint European cohort study. BMJ 2008;337:al 754 .

55. Mesher D, Szarewski A, Cadman L, Cubie H, Kitchener H, Luesley $D$, et al. Long-term follow-up of cervical disease in women screened by cytology and HPV testing: results from the HART study. Br J Cancer 2010;102(9):1405-1410.

56. Cuzick J, Szarewski A, Mesher D, Cadman L,Austin J, Perryman K, et al. Long-term follow-up of cervical abnormalities among women screened by HPV testing and cytology-Results from the Hammersmith study. Int J Cancer 2008; I22(I0):2294-2300.

57. Szarewski A, Ambroisine L, Cadman L,Austin J, Ho L, Terry G, et al. Comparison of predictors for high-grade cervical intraepithelial neoplasia in women with abnormal smears. Cancer Epidemiol Biomarkers Prev 2008; I7(II):3033-3042.

58. McIntyre PB, Brotherton JM, Burgess MA, Kemp AS. More data from Australia on sensitivity to HPV vaccine. BMJ 2009;338:b26.

59. Schiller JT, Castellsague X,Villa LL, Hildesheim A. An update of prophylactic human papillomavirus $L I$ virus-like particle vaccine clinical trial results. Vaccine 2008;26 Suppl 10:K53-K6I.

60. Kovacs K, Varnai AD, Bollmann M, Bankfalvi A, Szendy M, Speich N, et al. Prevalence and genotype distribution of multiple human papillomavirus infection in the uterine cervix: a 7.5-year longitudinal study in a routine cytology-based screening population in West Germany.J Med Virol 2008;80(10):1814-1823.

6I. Sigurdsson K, Sigvaldason H, Gudmundsdottir T, Sigurdsson R, Briem $H$. The efficacy of HPV I6/I8 vaccines on sexually active I8-23 year old women and the impact of HPV vaccination on organized cervical cancer screening. Acta Obstet Gynecol Scand 2009;88(I):27-35.

62. Perez G, Lazcano-Ponce E, Hernandez-Avila M, Garcia PJ, Muñoz N, Villa LL, et al. Safety, immunogenicity, and efficacy of quadrivalent human papillomavirus (types $6,11,16,18$ ) LI virus-like-particle vaccine in Latin American women. Int J Cancer 2008; 122(6):I3II-13 I8.

63. Joura EA, Leodolter S, Hernandez-Avila M,Wheeler CM, Perez G, Koutsky LA, et al. Efficacy of a quadrivalent prophylactic human papillomavirus (types $6,1 \mathrm{I}, 16$, and I8) LI virus-like-particle vaccine against high-grade vulval and vaginal lesions: a combined analysis of three randomised clinical trials. Lancet 2007;369(9574): 1693-I702.

64. Paavonen J, Jenkins D, Bosch FX, Naud P, Salmeron J, Wheeler CM, et al. Efficacy of a prophylactic adjuvanted bivalent LI virus-like-particle vaccine against infection with human papillomavirus types 16 and 18 in young women: an interim analysis of a phase III double-blind, randomised controlled trial. Lancet 2007;369(9580):2161-2।70.

65. Giuliano AR, Lazcano-Ponce E,Villa L, Nolan T, Marchant C, Radley $D$, et al. Impact of baseline covariates on the immunogenicity of a quadrivalent (types $6,11,16$, and 18) human papillomavirus virus-likeparticle vaccine. J Infect Dis 2007; 196(8): I I53-I I62.

66. Reisinger KS, Block SL, Lazcano-Ponce E, Samakoses R, Esser MT, Erick J, et al. Safety and persistent immunogenicity of a quadrivalent human papillomavirus types $6,1 \mathrm{I}, 16,18 \mathrm{LI}$ virus-like particle vaccine in preadolescents and adolescents: a randomized controlled trial. Pediatr Infect Dis J 2007;26(3):201-209.

67. Hildesheim A, Herrero R, Wacholder S, Rodriguez AC, Solomon D, Bratti MC, et al. Effect of human papillomavirus $16 / / 8 \mathrm{LI}$ viruslike particle 
vaccine among young women with preexisting infection: a randomized trial. JAMA 2007;298(7):743-753.

68. Paavonen J. Baseline demographic characteristics of subjects enrolled in international quadrivalent HPV (types 6/I I//6/18) vaccine clinical trials. Curr Med Res Opin 2008;24(6):1623-1634.

69. Tovar JM, Bazaldua OV. New quadrivalent HPV vaccine developments. Postgrad Med 2008;120(4):14-16.

70. Joura EA, Kjaer SK, Wheeler CM, Sigurdsson K, Iversen OE, Hernandez-Avila M, et al. HPV antibody levels and clinical efficacy following administration of a prophylactic quadrivalent HPV vaccine. Vaccine 2008;26(52):6844-685I.

71. Schwarz TF, Leo O. Immune response to human papillomavirus after prophylactic vaccination with ASO4-adjuvanted HPV-16/18 vaccine: improving upon nature. Gynecol Oncol 2008; I I0(3 Suppl I):SI-SIO.

72. Block SL, Nolan T, Sattler C, Barr E, Giacoletti KE, Marchant CD, et al. Comparison of the immunogenicity and reactogenicity of a prophylactic quadrivalent human papillomavirus (types 6, II, I6, and I8) LI virus-like particle vaccine in male and female adolescents and young adult women. Pediatrics 2006; I | 8(5):2135-2। 45 .

73. OIsson SE,Villa LL, Costa RL, Petta CA,Andrade RP, Malm C, et al. Induction of immune memory following administration of a prophylactic quadrivalent human papillomavirus (HPV) types 6/I I//6//8 LI virus-like particle (VLP) vaccine. Vaccine 2007;25(26):493I-4939.

74. Stanley M. Prospects for new human papillomavirus vaccines. Curr Opin Infect Dis 2010;23(I):70-75.

75. Morris SK, Nguyen CK. The human papillomavirus vaccine in Canada. Can J Public Health 2008;99(2): I I4-I I6.

76. Lazcano-Ponce E, Salmeron-Castro J, Garcia-Carranca A,Aranda-Flores C, Madrid-Marina V, Gomez-Altamirano CM, et al. [Recommendations for the definition of a policy on vaccination against papillomavirus in Mexico. Strategic Advisory Group of Experts of the World Health Organization]. Salud Publica Mex 2009;5I (4):336-34I. 